\title{
A área de influência da BR 163 no Estado do Mato Grosso: desmatamento e sua relação com a saúde ambiental no município de Guarantã do Norte*
}

\section{The area of influence of the BR 163 in the State of Mato Grosso: Deforestation and its relationship with environmental health in the municipality of Guarantã North}

\section{Resumo}

$\mathrm{O}$ artigo analisa as causas/consequências do desmatamento/queimadas e sua relação com o aumento do número de atendimentos ambulatoriais por problemas respiratórios entre crianças de 0 a 5 e idosos com mais de 65 anos no período de 2009/2012 no Município de Guarantã do Norte, no estado do Mato Grosso.

Palavras-chave: Queimadas. BR 163. Saúde. Meio Ambiente.

\begin{abstract}
The article analyzes the causes / consequences of deforestation / burned and its relation to the increase in the number of primary care visits for respiratory problems among children $0-5$ years and seniors over 65 years from 2009 to 2012 in the Municipality of Guarantã North, in the state of Mato Grosso.
\end{abstract}

Keywords: Burned. BR 163. Health. Environment.

Recebido em: 30/04/2015.

Aprovado em: 29/05/2015.

1 Mestre em Políticas Públicas e Desenvolvimento Sustentável. Coordenadora da Pós-Graduação em Direito/UniCEUB. E-mail: lilian.rocha@uniceub.br 


\section{Introdução}

O município escolhido para o desenvolvimento deste artigo foi o de Guarantã do Norte, situado na subárea do extremo norte do Mato Grosso. A área foi alvo de colonização do INCRA por empresas particulares e assentamentos governamentais, o que ocasionou um modelo econômico baseado na extração de recursos naturais, tendo como via de consequência o desmatamento (queimadas), proporcionando um aumento considerável de riscos para a saúde e para o meio ambiente do município e toda região.

Este artigo identificará e mapeará a dinâmica de queimadas na região da Amazônia Legal, especificamente no norte do estado do Mato Grosso e no município ora pesquisado, na tentativa de explicar suas principais condicionantes, baseando-se em análises espaciais e estatísticas, desenvolvidas com dados de queimadas, de variáveis ambientais, econômicas, sociais e dados de internações por problemas respiratórios na população do município.

No cenário do município ora estudado o desmatamento e os riscos à saúde, encontram-se associados à transformação intensa do meio ambiente, decorrente de diferentes formas de ocupação, de abertura de estradas, da expansão pecuária bovina e da agricultura da soja.

A acelerada dinâmica de uso de terras e a elevada incidência de pontos de queimadas observadas na Região da Amazônia Legal, principalmente na área de influência da BR-163, atingem proporções alarmantes, atraindo a atenção de ambientalistas, políticos e, especialmente, de gestores da área de saúde.

Não se pode falar que não existem políticas de monitoramento orbital e controle de queimadas, com o objetivo de conter o deslocamento e o avanço da fronteira agrícola sobre as áreas de vegetação natural, principalmente, para deter o avanço sobre a Floresta Tropical Úmida. Na Amazônia o processo de ocupação possui características e dinâmicas muito específicas e particulares.

O estado do Mato Grosso, mais especificamente o norte do estado, vem num processo de ocupação com características e dinâmicas muito particulares. É forte responsável pelo incremento de queimadas na região, em função da forma consolidada entre os diferentes atores do contexto exploratório dos recursos naturais e dos diferentes modelos e arranjos produtivos extrativistas, agropecuários, energéticos e minerados da região.

O uso do fogo é uma prática internalizada na re- gião, com finalidades absolutamente próprias e culturais e, portanto, a simples adoção de medidas proibitivas, punitivas, não vem obtendo resultados satisfatórios, causando o incremento do desmatamento e de queimadas que aumentam ano a ano na denominada região do arco do desmatamento.

Não se pode ignorar que a ocupação desordenada sem mecanismos regulatórios e de controle traz consigo enormes repercussões na saúde da população. O efeito das queimadas e o desmatamento na saúde dos habitantes deve-se ao modelo econômico prevalente na região da área de influência, o qual está baseado na extração de matéria-prima, madeira, levando a extensa devastação e deterioração de áreas. Além disso, têm-se como subprodutos: poluição e contaminação do solo pelo uso abusivo de agrotóxico. O modelo de desenvolvimento e de ocupação na região favorece o aparecimento de riscos para a saúde e o ambiente.

Ressalta-se que no município de Guarantã do Norte acontecem todos os tipos de problemas que alguma forma afetam a saúde ambiental, tais como a poluição dos rios pelo mercúrio dos garimpos, a contaminação da água por falta de infraestrutura de saneamento, a fumaça oriunda de queimadas pós-desmatamento, gerando alterações respiratórias, a grilagem de terra e a falta de ordenamento territorial gerando um palco de conflitos em toda a região e no município objeto da pesquisa.

$\mathrm{Na}$ situação ora em análise, o incremento do desmatamento e os efeitos das queimadas na saúde da população do município de Guarantã do Norte encontra-se associado à transformação intensa do meio ambiente e decorre de diferentes formas de ocupação e uso da terra. Destaca-se a abertura da BR-163, a expansão da pecuária bovina, a agricultura empresarial, a exploração da madeira e os projetos de colonização, com o estabelecimento de assentamento rural. É sabido que devido aos processos demográficos envolvidos nessas atividades, com maior adensamento populacional, as exposições aos riscos físico-biológicos tendem a ocorrer em escala maior, com repercussão epidemiológica.

Perante todas estas problemáticas que envolvem a saúde e o meio ambiente torna-se mais difícil avaliar o impacto dos fatores ambientais sobre a saúde. Logo, é importante perguntar até que ponto as mudanças ambientais têm afetado a saúde das pessoas?

Sabe-se que os grupos mais suscetíveis aos efeitos 
do desmatamento por via de queimadas são os de crianças, idosos e indivíduos portadores de doenças do aparelho respiratório e do sistema cardiovascular. Quanto às crianças, as doenças mais comuns que causam a maior taxa de morbimortalidade são aquelas que afetam o aparelho respiratório, em especial, as infecções respiratórias agudas, asma e bronquite. Este quadro ainda é agravado pela má nutrição, principalmente no grupo de baixo nível socioeconômico.

No caso dos idosos, embora a mortalidade seja mais relacionada aos problemas cardiovasculares, o principal motivo de morbidade ainda são as doenças do aparelho respiratório.

Existe, então, uma relação eminentemente concreta entre o meio ambiente e a saúde, sendo que a influência do primeiro pode ser positiva ou negativa. Positiva quando promove condições que propiciam a melhoria de vida das populações, e negativas quando geram condições para o aparecimento e disseminação de doenças dos mais diversos tipos, influenciando o padrão e o perfil dos níveis de morbimortalidade, nos mais diversos estratos populacionais. Logo, como introduzir boas práticas de saúde ambiental na região?

Este artigo se insere no escopo das reflexões do campo de estudo das Relações Internacionais por analisar, a partir do local, de que formas as políticas globais propostas para o alcance das metas de controle do desmatamento são vividas pelas comunidades afetadas e fragilizam o mecanismo de governança global sobre o meio ambiente.

\section{Causas e consequências históricas da forma de ocupação e desmatamento da região amazônica, do estado do Mato Grosso e da área de influência da BR -163}

Os agravos que podem ocorrer em interfaces do desmatamento e da ocupação são: a malária, os efeitos respiratórios de fumaça das queimadas, a contaminação mercurial e tantos outros que podem afetar a saúde, a qualidade de vida da população do município de Guarantã do Norte situado na área de influência da BR-163.

O desmatamento modifica a estrutura dos ecossistemas, resultando muitas vezes na fragmentação de habitats em pequenos trechos separados por atividades agrícolas ou populações humanas. Entretanto, o processo de degradação ambiental não se limita apenas às áreas ur- banas. O desmatamento acumulado da Amazônia Legal teve uma variação de -29 \% entre os anos de 2011 e 2012, como revelam os dados da Tabela 1.

Tabela 1 - Evolução do Desmatamento na Amazônia Legal

\begin{tabular}{|c|c|c|c|c|c|c|c|c|c|c|c|}
\hline & 2004 & 2005 & 2006 & דרסרת & 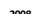 & 2009 & 2010 & 2011 & 2012 & $20072-201$ & $2012-2000$ \\
\hline Acre & $\frac{2004}{728}$ & $\frac{2005}{592}$ & $\frac{2006}{398}$ & $\frac{2007}{184}$ & $\frac{2008}{254}$ & $\frac{2009}{167}$ & $\frac{2010}{259}$ & $\frac{2011}{280}$ & $\frac{2012}{305}$ & $\frac{2012.2011}{9 \%}$ & 2012.2004 \\
\hline Amazonas & 1232 & 775 & 788 & 610 & 604 & 405 & 595 & 502 & 523 & $4 \%$ & $.58 \%$ \\
\hline Amapá & 46 & 33 & 30 & 39 & 100 & 70 & ${ }_{53}$ & 66 & 27 & $.59 \%$ & $.41 \%$ \\
\hline Maranhão & 755 & 922 & 674 & 631 & 1271 & 828 & 712 & 396 & 269 & $-32 \%$ & $.64 \%$ \\
\hline $\begin{array}{l}\text { Marannao } \\
\text { Mato Grosso }\end{array}$ & $\begin{array}{l}18514 \\
11814\end{array}$ & $\begin{array}{l}7142 \\
7145\end{array}$ & $\begin{array}{l}4333 \\
4333\end{array}$ & $\begin{array}{l}2511 \\
2678\end{array}$ & 3258 & $\begin{array}{l}828 \\
1049\end{array}$ & 871 & 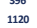 & $\begin{array}{l}269 \\
757\end{array}$ & $.32 \%$ & . \\
\hline Pará & 8870 & 5899 & 5659 & 5526 & 5607 & 4281 & 3770 & 3008 & 1741 & $-42 \%$ & $.80 \%$ \\
\hline Rondônnia & $\begin{array}{l}5858 \\
3858\end{array}$ & 3244 & 2049 & 1611 & 1136 & 482 & 435 & 865 & 73 & $.11 \%$ & $-80 \%$ \\
\hline Roraima & $\begin{array}{l}3000 \\
311\end{array}$ & 133 & 231 & 309 & 574 & $\begin{array}{l}212 \\
121\end{array}$ & 256 & ${ }_{141}^{140}$ & ${ }_{124}$ & $-11 \%$ & $.60 \%$ \\
\hline Tocantins & 158 & 271 & 124 & 63 & 107 & 61 & ${ }_{49}$ & 40 & 52 & $30 \%$ & $-67 \%$ \\
\hline Amazonnia Legal & 2772 & 19014 & 14286 & 11651 & 12911 & 7464 & 7000 & 6418 & 4571 & $-29 \%$ & $-84 \%$ \\
\hline
\end{tabular}

Também nota-se que para a região da Amazônia Legal durante o período de 2004 a 2012 apresentou uma variação de $84 \%$. No estado do Mato Grosso, nota-se que o desmatamento acumulado vem reduzindo de 2004 a 2012, entretanto o desmatamento na região é permanente ora com picos de alta ora com redução das queimadas.

Apesar do fato de todos os conflitos na região serem oriundos do modelo de desenvolvimento adotado no país, são eles de alguma forma decisivos na mediação entre desenvolvimento e saúde no Brasil, tais como a presença de uma malha de meios de transporte e comunicações, visando a difusão de informações, a expansão da fronteira agrícola e a integração das regiões do Norte e Centro-Oeste, a criação de grandes rodovias como forma de escoamento de produção. De algum modo, estes processos foram decisivos para inúmeras transformações ambientais que vêm afetando as condições de vida e bem- estar das populações do arco do desmatamento.

Na região amazônica até a década de 50, a ocupação e produção eram agropecuárias e caracterizaram-se por uma atividade pecuária de pouca expressão. Inicialmente, estas atividades foram desenvolvidas sobre pastagens naturais e várzeas, distribuídas nos estados do Pará, Tocantins, Mato Grosso e Roraima.

A densidade territorial, aliada à sua baixíssima densidade populacional, já despertava enorme interesse internacional, delineando forte necessidade de estabelecer uma reconhecida soberania, mesmo nas áreas isoladas da região.

Era necessária a criação de uma política de ocupação (povoamento) da Amazônia, sendo meta prioritária a implantação de infraestrutura para viabilizar o acesso e incentivar a migração e a colonização (GONÇALVES, 2010).

A atual ocupação humana do espaço amazônico, particularmente no estado do Mato Grosso, deriva de um cenário de transformações e de um histórico de motivações políticas e ações. A evolução de tal ocupação está 
relacionada a algumas ações governamentais de incremento ao povoamento na região. Não se pode esquecer que durante este período surgiram vários instrumentos legais de controle e prevenção objetivando minimizar os impactos ambientais e sociais gerados nesse processo.

Nas décadas seguintes, várias estratégias foram adotadas para chamar a atenção da população brasileira e despertar o interesse pela região. Foram planejadas e construídas importantes rodovias na tentativa de criar redes de integração nacional. Vários projetos de colonização agrícola, públicos e privados tentavam atrair migrantes, na intenção de trazer estruturas produtivas da Amazônia conquistando, assim, novos empreendedores.

Muitos são os fatores acerca das causas do desmatamento da Amazônia Legal, tais como os movimentos populacionais, o crescimento urbano, especialmente os induzidos, configurando assim a ocupação do solo, a pecuária, o garimpo, madeireiros aliados a forte pressão econômica e a apropriação dos recursos naturais por diversos atores envolvidos no processo, conforme Diniz et al (2007).

Este foi o padrão predominante nas décadas de 60 e 70, cujos atores foram motivados pela consolidação de grandes eixos viários de integração como forma acelerada de ocupação.

No início da década de 80 , o desenvolvimento e a expansão da atividade agropecuária, bem como o comércio de madeira, reforçaram o modelo de ocupação e a consequente explosão das taxas de desmatamento e o aumento de queimadas na região, especialmente no norte do Mato Grosso, na área de influência da BR 163 que une o estado do Mato Grosso ao Pará.

O Governo Federal, avaliando as políticas públicas de ocupação acelerada e desordenada, resultado de suas próprias ações, visando o povoamento da região, reduziu os incentivos à ocupação na região Amazônica, na tentativa de controlar a situação e diminuir as alarmantes taxas de queimadas de floresta natural. Entretanto, os índices de desmatamento persistem na região Amazônica e norte do Mato Grosso.

Quanto às causas do desmatamento em um amplo estudo sobre os fatores responsáveis pelo desmatamento de florestas tropicais, (HELMUT; LAMBIN, 2001), por meio da análise de diversos estudos de caso em todo mundo, concluíram que as causas podem ser divididas em dois tipos: diretas e indiretas. As causas diretas de mudança de uso do solo da floresta, segundo os autores, são a expansão da agricultura (incluindo a agricultura familiar, a agricultura de grande escala, pecuária, colonização, assentamento e transmigração); a extração da madeira; e a extensão de infraestrutura (transportes, mobilidade urbana, assentamentos rurais, usinas hidrelétricas e mineração). Entre as causas indiretas, ou seja, aquelas originadas de processos sociais que determinam as causas diretas estão: demografia (dinâmica das populações humanas e ou pressão populacional, fatores econômicos (comercialização, desenvolvimento, crescimento ou mudança econômica); fatores tecnológicos (mudança ou avanço tecnológico); fatores institucionais e políticos (mudança ou impacto de instituições político-econômicas, mudanças institucionais) e um complexo de fatores sócio-políticos ou culturais (valores, atitudes públicas e crenças).

Geist e Lambin (2002) basearam seus estudos em 152 casos de desmatamento tropical em escala subnacional localizados na Ásia (36\% dos casos em 10 países), na África ( $13 \%$ dos casos em 8 países) e na América Latina (51\% dos casos em 11 países), e os resultados alcançados nestes estudos relacionados às causas diretas do desmatamento foram: a) as causas diretas do desmatamento isoladamente explicam muito pouco o desmatamento, sendo que próximo de $96 \%$ de todos os casos relatados têm mais de uma fator explicativo (resultado para todos os continentes estudados); b) dentre essa combinação de fatores explicativos, a expansão agropecuária em conjunto com uma até três causas é a mais frequente. $\mathrm{Na}$ América Latina o que mais explica o desmatamento em termos de frequência de ocorrência é a combinação de expansão de agropecuária com expansão de infraestrutura (32\% dos 78 casos estudados na Amazônia); c) em $82 \%$ dos casos analisados na América Latina a causa do desmatamento estava atrelada à criação de pastos; e d) outros fatores ligados ao tipo de solo e fatores climáticos são relatados em $34 \%$ do total dos casos, no entanto, nenhum desses fatores são reportados isoladamente como causa do desmatamento.

Quanto às causas indiretas do desmatamento avaliado pelos autores são: a) os fatores econômicos (81\%) são os mais prevalentes, se comparados à política e aos fatores institucionais (63\%), tecnológicos (59\%), sócio-político e cultural (56\%) e fatores demográficos $(51 \%)$, esses dados referem-se a todos os continentes onde os casos foram estudados; b) $\mathrm{Na}$ América Latina a influência dos casos de políticas informais (corrupção, falta de regulação, crescimento de 
coalizões de grupos, clientelismo, interesses privados influenciando regulamentações públicas e redefinição de objetivos políticos) foi de $41 \%$ sendo que o fraco desempenho do Governo e a falta de governança foi responsável por $31 \%$ do total; e c) na América Latina, todos os fatores ligados à demografia foram responsáveis por $53 \%$ das causas do desmatamento. Os fatores ligados à demografia foram responsáveis por $53 \%$ das causas do desmatamento. Dentre os fatores demográficos o que se apresenta mais relevante nessa região é o da migração de fazendeiros para áreas afetadas pelo desmatamento.

O desmatamento na região da Amazônia Legal e no norte do Mato Grosso apresenta uma dinâmica cíclica, ora com tendências de queda, ora de alta. É impossível explicar o desmatamento de uma região tão heterogênea como a Amazônia utilizando-se somente uma ou duas variáveis. Na verdade é um mosaico de causas, que se inter-relacionam e vão combinando no decorrer do tempo (ALENCAR et al, 2004), no entanto, há algumas causas que são mais comuns no contexto geral da região e do município ora objeto deste artigo (Figura 1).

Figura 1 - Mapa Causas do Desmatamento

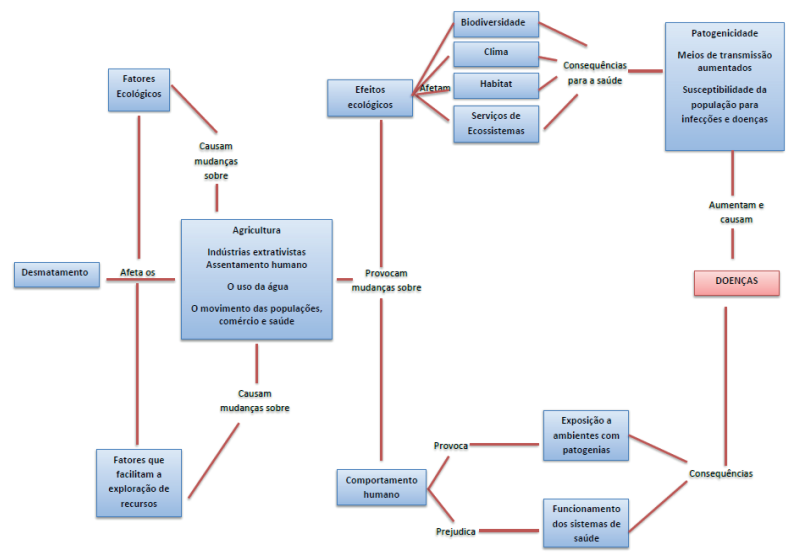

Fonte: Cronograma da análise dos efeitos do desmatamento. Elaboração própria.

Na literatura sobre o desmatamento da Amazônia Legal, alguns fatores são mais concorrentemente citados: a) políticas públicas - Programas de Desenvolvimento e Crédito, existe sem dúvida um consenso sobre o papel indutor do Estado na ocupação da Amazônia, durante a ditadura brasileira nas décadas de 60 e 70 , por meio da construção de infraestrutura e créditos subsidiados; b) construção de estradas, o aumento do desmatamento ao longo das estradas, pois essas estru- turas facilitam o estabelecimento de pessoas, estimulam a produção, além do aparecimento de estradas secundárias. Laurence et al. (2002, p. 742) indicam que, em média, o desmatamento eleva-se acentuadamente entre 50 a $100 \mathrm{~km}$ das rodovias pavimentadas e entre 25 a $50 \mathrm{~km}$ das rodovias sem pavimentação, confirmado por Becker (2002) que observou que 95\% dos desmatamentos, total entre 1991 a 1997, localizavam-se a uma distância de até $100 \mathrm{~km}$ das maiores rodovias.

Analisando o trecho da BR 163, não pavimentado, Nepstad et. al. (2001) concluem que até $50 \mathrm{~km}$ de distância somente $5 \%$ foram desmatados na parte não pavimentada em relação à proporção de $26 \%$ a $58 \%$ de desmatamento em torno de estradas pavimentadas há 20 e 30 anos atrás; c) implantação de pastagens de gado, políticas públicas que promoveram o desenvolvimento de pastagens para o gado foram o primeiro vetor para o desmatamento na região amazônica, e a conservação de floresta para pastagens tornou-se a forma predominante de desflorestamento, segundo Nepstad et al. (2006) sendo que até recentemente a implantação de pastagens era responsável por $2 \backslash 3$ do desflorestamento anual da Amazônia; d) agricultura - cultura da soja, conforme Fearneside (2000), a soja também representa um vetor que vai além do desmatamento direto das áreas, visto que essa cultura justificaria o investimento maciço de recursos públicos em obras de infraestrutura, conhecido como o efeito arrasto; e) desmatamento (queimadas) vale destacar que de acordo com o Instituto de Pesquisa Ambiental da Amazônia (IPAM), entre os anos de 2012 e 2013 a taxa de desmatamento aumentou na Amazônia de forma (28\%), incremento este que deve ser considerado inaceitável por três motivos principais: o desmatamento em questão foi, em grande parte, ilegal; existe na região amazônica uma grande quantidade de área já desmatada, porém subutilizada; e o poder público brasileiro já possui elementos fundamentais para combater o desmatamento amazônico.

Embora a área desmatada nesse período (5.843 $\mathrm{km}^{2}$ ) seja a segunda mais baixa registrada desde o início do monitoramento do Instituto Nacional de Pesquisa Espacial (INPE), ainda representa um grande desperdício, pois sobra na Amazônia uma grande área já desmatada e que se encontra completamente subutilizada. (Figura 2) 
Figura 2 - Desmatamento na Área de Influência da BR-163

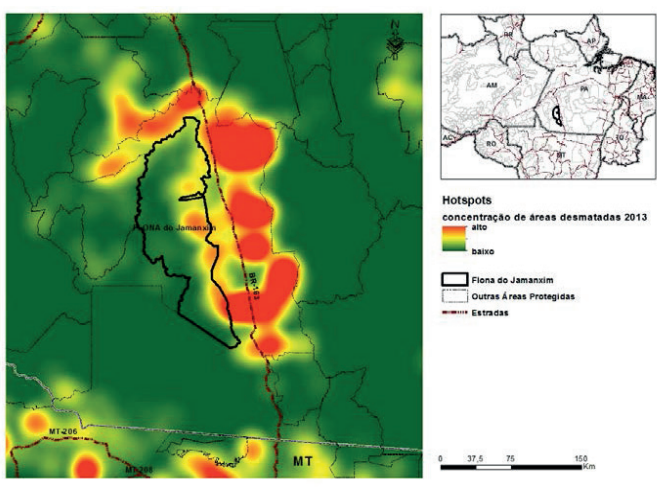

Fonte: INPE ${ }^{2}$.

O desmatamento, como pode ser observado a seguir, continua avançando em terras públicas não destinadas, isto é, milhões de hectares de terras desflorestadas que aguardam destinação, os quais estão à mercê de grileiros e especuladores de terra. Assim, cabe ao Governo coordenar e focar as ações de vários órgãos responsáveis como o Serviço Florestal Brasileiro, Ibama, ICMbio, Incra e Funai. Percebe-se que os focos de calor/queimadas permanecem na região da BR 163, na área do município de Guarantã do Norte.

O gráfico 1 apresenta a evolução anual da taxa de desmatamento na Amazônia, ou seja, uma série histórica que compreende o período entre os anos de 2004 a 2013, assim, observa-se que após a implantação de políticas públicas na região houve uma redução do desmatamento entre 2004 a 2013. Contudo no decorrer do período houve um aumento do desmatamento na Amazônia de 11\% (2007-2008) e de 28\% (2012-2013).

Gráfico 1 - Evolução da Taxa Anual do Desmatamento na Amazônia

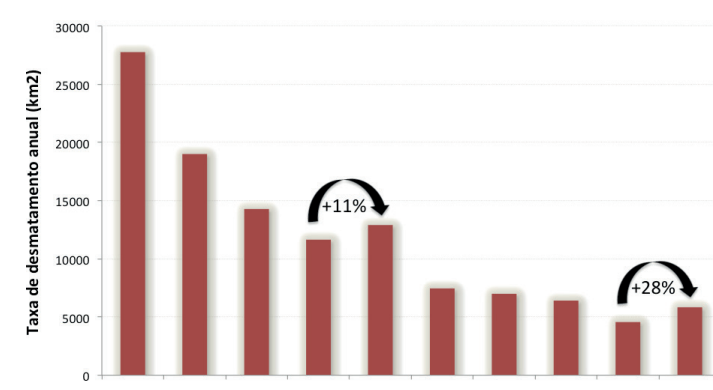

2 Os hotspots de desmatamento em 2013 na região da BR-163/ Flona do Jamanxim. Cada hotspot é delineado através do cálculo (Análise de Densidade de Kernel) da densidade de polígonos de desmatamento de diferentes tamanhos ocorridos ao longo do ano de 2013.
Fonte: PRODES, INPE ${ }^{3}$. As setas indicam as percentagens de aumento nas taxas em dois momentos a partir de 2004: 2007-2008 e 2012-2013.

O estado do Mato Grosso é a área escolhida para o desenvolvimento deste artigo, especificamente o município de Guarantã do Norte. O Mato Grosso está localizado na região Centro-Oeste do Brasil. Nesta área ocorre a incidência de cerrados brasileiros, da floresta tropical úmida e da planície do pantanal, o estado apresenta uma grande diversidade de situações ecológicas, sociais, econômicas, culturais e de processos de produção. De acordo com dados do Instituto Brasileiro de Geografia e Estatística (IBGE), a extensão territorial de $906.069 \mathrm{~km}^{2}$ é distribuída em 141 municípios e uma população estimada para 2013 de 3.182.114 habitantes.

Nas últimas décadas, o estado do Mato Grosso assumiu papel de destaque no cenário nacional, ora por apresentar elevados índices de crescimento econômico, produção agrícola e pecuária, ora por ser apontado como o responsável por uma das maiores taxas de erradicação de cobertura vegetal natural, sobretudo na região do cerrado e na floresta tropical úmida. Este fato coloca o estado numa incômoda posição de possuir os maiores índices anuais de desmatamento e de ocorrência de queimadas do país, dividindo as primeiras posições juntamente com os estados do Pará e do Amazonas.

Essas características fazem com que o Mato Grosso devido ao fato de possuir uma diversidade de fatores ecológicos, fundiários e econômicos venha se tornando nas últimas décadas uma fonte para pesquisas de influência do desmatamento por via de queimadas, na saúde humana. Ao se observar o gráfico do desmatamento da Amazônia Legal, nota-se, de imediato que o estado do Mato Grosso lidera quantitativamente em relação aos outros, na maioria dos anos ilustrados, conforme Becker (2002), sobre o tipo de desenvolvimento que o estado trilhou nos últimos anos não reproduzindo uma fronteira socioambiental e sim agrícola. Fator agravante da situação foi a implantação da Rodovia BR 163 que liga Cuiabá a Santarém, no Estado do Pará, que na verdade é uma rodovia com $3.467 \mathrm{~km}$ de extensão ligando Tenente Portela, no Rio Grande do Sul, a Santarém no Pará.

Esta rodovia trouxe, e ainda vai trazer muito mais, progresso para a região, mas não obstante seus potenciais benefícios sociais e econômicos, também trouxe em contrapartida os impactos socioambientais, como a ace-

3 Coordenação geral de observação da terra. Disponível em: <www.obt.inpe.br/prodes/index.php >. Acesso em: 10 jan 2014. 
leração da grilagem, a ocupação ilegal de terras públicas, as migrações desordenadas, a concentração fundiária, o desmatamento (queimadas) e a precarização das condições de saúde pública.

Assim, a presença ainda insuficiente do poder público e as políticas inadequadas para a região são fatores agravantes do cenário quase caótico do estado, no que diz respeito à exploração predatória dos recursos naturais.

\section{Características socioambientais do munícipio de Guarantã do Norte}

O município de Guarantã do Norte, localizado a $725 \mathrm{~km}$ de Cuiabá, fica às margens da BR-163, com área de $4.732,38 \mathrm{~km}^{2}$, e população de 32.216 habitantes, sendo a densidade demográfica de $6,79 \mathrm{hab} \backslash \mathrm{km}^{2}$. O índice de desenvolvimento humano é de 0,799 e sua taxa de urbanização em 2010 de 74,31\%, entre 2000 e 2010; a população de Guarantã do Norte teve uma taxa de crescimento anual de 1,34\%. O clima do município é típico da região, ou seja, tropical chuvoso e o solo de baixa fertilidade, propício para atividades agropastoris desde que incrementado pelo uso de fertilizantes.

Figura 3 - Guarantã do Norte

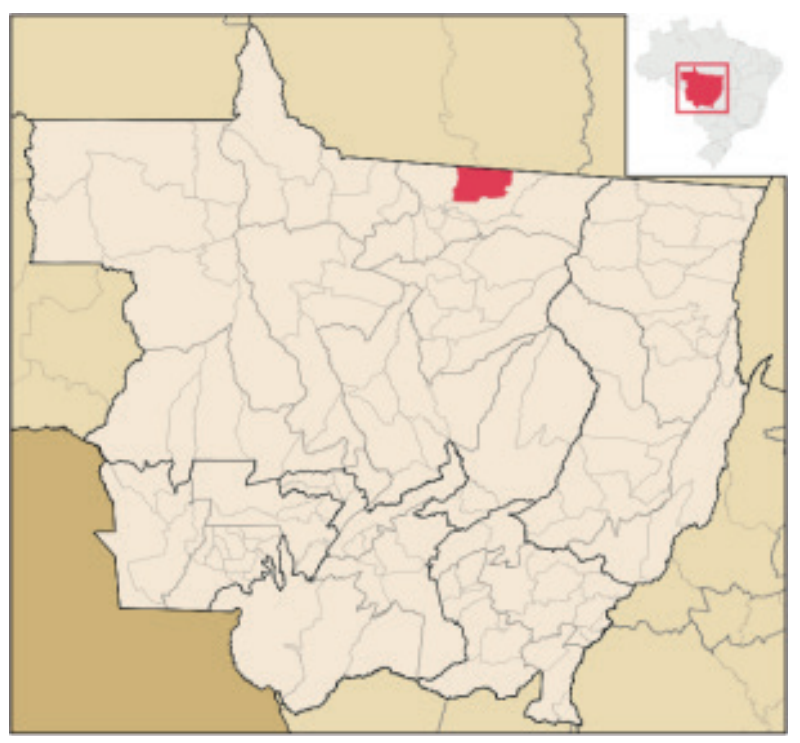

Fonte: Atlas Geográfico (2013)

Com o programa de colonização nas áreas prioritárias para fins de Reforma Agrária e Segurança Nacional, através do INCRA, entre os anos de 1970 e 1980, famílias vinham do Rio Grande do Sul (formaram a Vila Cotrel), logo em seguida a chegada dos "brasiguaios" e, no ano de 1982, os moradores da região e as autoridades representativas de órgãos estaduais lavraram a Ata de Fundação para em 1984 elevar a Vila Cotrel à categoria de Distrito de Colíder. No dia 13 de Maio de 1986 Guarantã do Norte transformou-se em município. Sua economia está diversificada e baseada na pecuária, incluindo uma das maiores bacias leiteiras da região e a agricultura, tem na cultura do arroz sua maior expressividade.

No que tange o índice de desenvolvimento humano municipal durante o período de 1991 a 2000, o IDHM apresentou uma evolução em sua taxa de crescimento (48,46\%) passando de 0,357 em 1991 para 0,530 em 2000, na mesma década o hiato de desenvolvimento humano reduziu para $26,91 \%$.

Conforme os dados do IDHM (Gráfico 2), entre os anos de 2000 e 2010 uma taxa de crescimento de 32,64\%, o IDHM passou de 0,530 para 0,703 respectivamente.

Gráfico 2 - Evolução do IDHM - Guarantã do Norte - MT

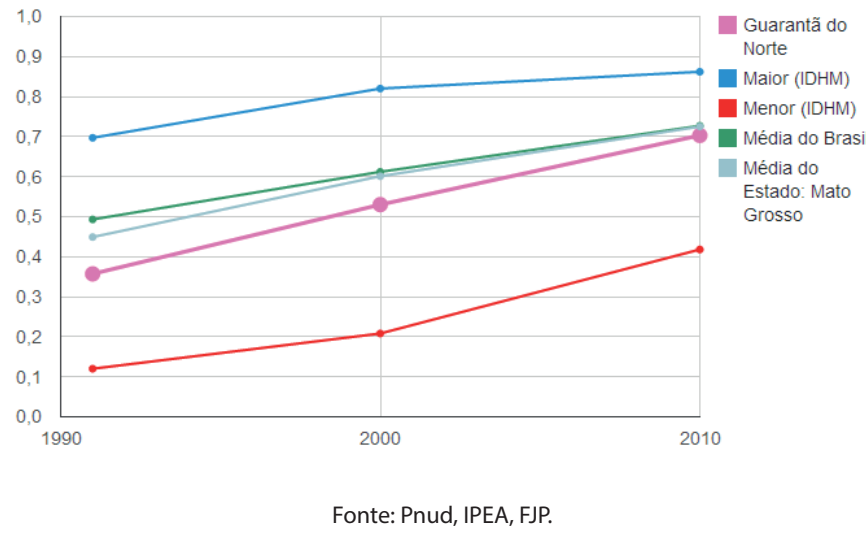

Os resultados revelam que o hiato de desenvolvimento humano apresentou uma redução de 36,81\% para o mesmo período. Durante os anos de 1991 e 2000 e os anos de 2000 e 2010, a taxa medida de crescimento anual apresentada foi de 1,02\% para as duas décadas. De acordo com dados do Atlas de Desenvolvimento Humano (2013), a estrutura etária populacional, os resultados revelam que a razão de dependência apresentou uma redução de $11,31 \%$, enquanto o índice de envelhecimento evoluiu 1,19\%. Em 1991, o município apresentava um alto nível de natalidade e a esperança média de vida estava entre 60 e 64 anos. Durante o ano de 2000, Guarantã do Norte apresentou uma redução em seu índice de natalidade e sua esperança média de vida passou de 65 para 69 anos, apresentando uma elevação na expectativa de vida. Após duas décadas o município de Guarantã do Norte apresenta uma redução de $7,92 \%$ na natalidade e uma elevação em sua expectativa de vida de $1,0 \%$, ou seja, a região tem uma 
diminuição da natalidade e um aumento da esperança média de vida para 74 anos.

O desmatamento no município foi incrementado desde o inicio da obra da BR-163, segundo Mahar (1979), na medida em que se ampliavam as áreas de pecuária bovina, o emprego do fogo foi sendo fomentado, principalmente devido aos incentivos fiscais como fortes condutores do desmatamento, além de incentivar a ocupação e urbanização das área ao longo da BR-163, ocasionando um aumento acelerado neste processo. $\mathrm{O}$ desmatamento para Alencar et al. ( 2005) é definido como um fenômeno de natureza complexa que a exploração seletiva e predatória de madeiras funciona como uma espécie de "cabeça de pote" do desmatamento na região. A região do norte do Mato Grosso apresenta altos índices de desflorestamento com o aumento de queimadas, o que resulta em elevação dos problemas respiratórios, principalmente, em crianças menores de 5 anos e idosos. No município objeto deste artigo e de acordo com dados do Instituto Nacional de Pesquisa Espacial (INPE) verifica-se o incremento e a extensão do desmatamento. Conforme dados do INPE (2012), o Município de Guarantã do Norte em 2009 registrou 2.387.8 quilômetros quadrados (50,62\%) de perda florestal e, em 2012, 2.406 .0 quilômetros quadrados (61,01\%). Observa-se que o município desde 2001 vem reduzindo sua cobertura florestal, ora com picos de desmatamento ora com índices de redução, mas de forma permanente acontece o desmatamento no município. É alarmante esse índice, daí resta a pergunta: Como minimizar os efeitos das queimadas na saúde da população do município?

\section{Os efeitos das queimadas na saúde}

Os eventos decorrentes da poluição ambiental, da queima de combustíveis fósseis, os desmatamentos e as queimadas, além de afetarem a qualidade do ar atmosférico, afeta, principalmente, a saúde humana. De acordo com Ribeiro (2000) as emissões de material particulado e o monóxido de carbono, originados pelos focos de calor, podem contribuir para a má qualidade do ar e influenciar doenças respiratórias. Assim, com o intuito de atender aos objetivos deste estudo, serão analisados os altos índices de desmatamento que podem estar relacionados com o índice de atendimentos ambulatoriais relacionados à doenças respiratórias no município de Guarantã do Norte. Fatores das. Pesquisas realizadas por Radojevic \& Hassan (1999) em Brunei Darussalam, indicam alguns dos efeitos que as queimadas de florestas desencadeiam na região, ou seja, provoca uma drástica redução da visibilidade, o que ocasiona o fechamento de aeroportos e escolas, além do aumento de acidentes de tráfego aéreo, destruição da biota pelo fogo, diminuição da produtividade, restrição das atividades de lazer e trabalho e a elevação dos custos econômicos. Também, observaram o aumento da incidência de enfermidades e, dentre os sintomas observados relatam-se infecções do sistema respiratório superior, asma, conjuntivite, irritação dos olhos e garganta, tosse, falta de ar, nariz entupido e desordens cardiovasculares. Em Araraquara, São Paulo um estudo transversal desenvolvido por Arbex durante o período de $1^{\circ}$ de julho a 31 de agosto de 2000, concluiu que a queima de cana-de-açúcar pode ter efeitos deletérios a saúde da população exposta. Os dados foram comparados aos números de visitas hospitalares e de pacientes que necessitaram de inalação em um dos principais hospitais da cidade. Entretanto, os autores salientam que vários fatores contribuíram para a piora da qualidade do ar durante a safra da cana além da queimada, tais como maior movimentação de caminhões e máquinas e poeira das estradas. Na região de Bauru, São Paulo, Lopes e Ribeiro (2006) verificaram uma possível correlação entre as emissões das queimadas de cana-de-açúcar e os registros de problemas respiratórios, através de técnicas de geoprocessamento.

Souza (2008) desenvolveu um estudo ecológico no município de Rio Branco, Acre durante o período de 2000 a 2006, relacionando o aumento dos focos de calor captados pelos sensores AVHRR/ NOAA com as internações hospitalares em crianças menores de 4 anos e idosos com idade superior a 65 anos. Pelos resultados, observou uma relação e aumento do número de internações em comparação à quantidade de focos de calor. Estudos que avaliaram os efeitos das queimadas na Amazônia e seus efeitos na saúde da população como de Hacon (2007), o qual realizou um estudo ecológico dos indicadores de morbidade hospitalar e mortalidade por doenças do aparelho respiratório em menores de 5 anos no período de 2000 a 2004. Analisou a proporção de internações por doença do aparelho respiratório em menores de 5 anos para o cálculo de escores e definição do ranking dos municípios. O estudo considerou a localização geográfica dos municípios, tipo de bioma, estrutura da rede de serviços de saúde, número de habitantes, registros dos dados ambientais 
prévios de poluentes atmosféricos e de dados meteorológicos. E selecionou os municípios de Alta Floresta e de Tangará da Serra para o desenvolvimento da pesquisa. Os resultados foram que os indicadores de saúde mostram uma consistência e orientam a análise integrada de saúde e ambiente.

Minayo e Miranda (2002) apontam que a "emergência e reemergência" de doenças no mundo atual estão fortemente potencializadas pela interação dos fenômenos da degradação socioecológica, dos interesses econômicos, da deterioração dos programas de saúde pública, da globalização rápida de padrões de comportamentos sociais. Esta degradação sociecológica está associada a intensas transformações sociais, direcionadas pelos interesses econômicos, alicerçada no desenvolvimento predatório. Como resultado, tem-se o aparecimento de novas doenças, recrudescimento de outras e exposição populacional a riscos antes não existentes. Assim, sendo todos esses novos e antigos fatores, muitas vezes negligenciados, colaboram para desenhar o complexo cenário que envolve a saúde, como exemplificado abaixo.

Tabela 2: - Fatores que influenciam na emergência das doenças infecciosas.

$\begin{array}{ccc}\text { Fator } & \begin{array}{c}\text { Exemplos de fatores } \\ \text { específicos }\end{array} & \text { Exemplos de doenças } \\ & \begin{array}{c}\text { Agricultura, represas, } \\ \text { desflorestamento, } \\ \text { enchentes/secas, fome, } \\ \text { mudanças climáticas }\end{array} & \begin{array}{c}\text { Leishmaniose, } \\ \text { Arbovirus (Sabiá, Rocio, } \\ \text { Mayaro), Hantavirose }\end{array} \\ \text { Mudanças ecológicas } & \\ \text { Cemografia e } & \begin{array}{c}\text { guerras, deteriorização } \\ \text { dos centros urbanos, } \\ \text { comportamental }\end{array} & \text { Dengue, Tuberculose } \\ & \text { adensamento } & \end{array}$

Comércio e viagens internacionais

Adaptação às mudanças dos agentes

Colapso nas medidas de saúde pública

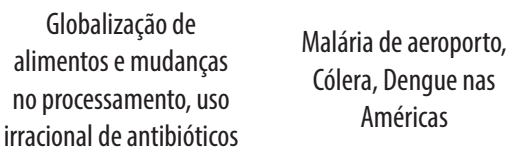

Evolução dos microorganismos, resistência

Saneamento e controle inadequado de vetores, cortes nos programas de prevenção
Cólera, dengue bactérias, resistência a antibióticos, pesticidas

\section{Análise da saúde do Município de Guarantã do Norte}

Por meio do Relatório das Informações Regionais de Saúde do Mato Grosso, nota-se que o Escritório Regional de Saúde (ERS) de Peixoto de Azevedo que atende os municípios de Guarantã do Norte, Novo Mundo e Peixoto de Azevedo no período analisado atendeu em 2009 um total de 5.460 indivíduos, sendo que destes, 1.834 eram procedentes de Guarantã do Norte, perfazendo um percentual de 33,6\% dos atendimentos no ERS. Estes dados mostram que a quantidade de pessoas atendidas provocam um forte vetor de pressão por serviços hospitalares no município, por si só extremamente carente em instalações de saúde. Guarantã do Norte possui apenas dois hospitais, sendo um público e um privado.

Deste total, o número de internações devido a DR (doenças respiratórias foi de 320 pacientes ( 17,45\%, sendo assim distribuídos por faixa etária, de zero a cinco anos 144 (45\%), maiores de sessenta anos 99(30.9\%). Em 2012 ,o ERS de Peixoto de Azevedo atendeu 5.438 indivíduos sendo 1563 provenientes de Guarantã do Norte, perfazendo um total de $28,7 \%$ do total. As internações devido a DR somam 185 pacientes, sendo distribuídos da seguinte maneira, de zero a cinco anos 69(37,3\%) e maiores de sessenta anos $87(47,1 \%)$. 
Um fato importante, é a discrepância dos dados de 2009 e 2012.Comparando os dois anos verifica-se, percentualmente, que em 2009 o número de internações por DR foi maior que 2012. A explicação de tal fato é que no período de 2008 para 2009, a região estava no auge do incremento do desmatamento, conforme Tabela 3 abaixo.

\section{Tabela 3}

\begin{tabular}{c|c}
\hline ANO & INCREMENTO DO DESMATAMENTO \\
\hline 2009 & $9,2(0,20 \%)$ \\
\hline 2012 & $4,2(0,09 \%)$ \\
\hline
\end{tabular}

Fonte: http://sisam.cptec.inpe.br/msaude/info.consulta.logic

É bom notar que em 2009, a morbidade foi maior nos pacientes de zero a cinco anos. Entretanto em 2012, a morbidade foi maior nos maiores de sessenta e cinco anos, idade em que os indivíduos são mais propensos a serem afetados por doenças respiratórias.

Quanto aos dados pertinentes à distribuição das principais causas de internação do ERS de Peixoto de Azevedo, as doenças do aparelho respiratório foi a terceira principal causa de internações, ou seja, foram 683 pessoas, perfazendo um total de $12,6 \%$ em 2012, sendo que em primeiro lugar foram as internações por gravidez parto e puerpério, com 1.085 pessoas, 18,8\% em 2012.. Quanto as principais causas de óbitos do ERS em 2012 as doenças do aparelho respiratório estão em quinto lugar com 4,9\% (20).

Diante do exposto verifica-se que existem vários problemas de saúde pública que podem atingir, mesmo que de forma diferenciada, diversos grupos populacionais, logo, é necessária a adoção de políticas públicas que visem melhorar a eficiência da saúde ambiental, e, consequentemente, a saúde da população.

\section{Procedimentos Metodológicos}

Com intuito de alcançar os objetivos propostos na pesquisa, ou seja, identificar a influência das queimadas na saúde da população do município de Guarantã do Norte, a análise foi realizada com base na seleção de um conjunto de indicadores, os quais procurou-se captar elementos e fatores determinantes de impactos na saúde. Foi utilizado um conjunto de dados extraídos do INPE, IMAZON, Monitoramento PRODES- INPE e da Secretária Estadual de Saúde, do Sistema Único de Saúde, e para incrementar a análise foi realizado grupo focal com aplicação de questionário em profissionais da área de saúde no município pesquisado, bem como o modelo Força Motriz, Pressão, Estado, Exposição e Efeitos (FPEEEA). Este modelo é utilizado para identificação e organização de dados existentes na construção de indicadores voltados à vigilância da saúde de populações e ambientes específicos, o que permite compreender os determinantes, em diferentes níveis, do uso de determinadas tecnologias ou processos que desencadeiam efeitos negativos sobre o ambiente e a saúde humana.

\section{Resultados}

O questionário constituiu-se de um instrumento estruturado com questões fechadas, escolhidas por sua característica de facilitar a interação do Grupo Focal. Verificou-se que os sintomas de doenças respiratórias são os mais frequentes no município durante o inverno (75\%) e no verão (25\%), o período onde ocorre o maior número de queimadas é entre junho/novembro. Ao serem questionados qual o grupo de indivíduos cuja incidência de DR é maior, constatou-se que $83,4 \%$ das crianças de 0 a 5 anos possuem doenças no aparelho respiratório. A avaliação dos dados também revelou que a taxa de morbidade devido a DR é maior em crianças de 0 a 5 anos $(66,7 \%)$, seguido pelo grupo de idosos de 33,3\%. Do grupo de entrevistados $75 \%$ afirmam que as queimadas são responsáveis por ocasionar as DRs. Quanto às condições de atendimento hospitalar dos pacientes com DR, dos entrevistados 25\% afirmam que o município está em condições de atender os pacientes portadores de doenças respiratórias, enquanto $75 \%$ informaram que o município não possui essas condições; verificou-se que 8,3\% disseram que o hospital do município não apresenta boa estrutura para atendimentos dos pacientes de DR. Os dados revelaram que $83,4 \%$ dos entrevistados alertam quanto à falta de profissionais de saúde, médicos, especialistas e $1 \%$ indica a falta de equipamentos adequados para o tratamento. Os resultados revelam que $83,4 \%$ dos entrevistados acreditam que o aumento das doenças respiratórias no município foi ocasionado pelo desmatamento ocorrido para implantação da BR-163 este é um vetor importante nessa área onde estão localizados 71 municípios cuja economia se baseia em atividades do setor primário, como agricultura, pecuária e extrativismo, principalmente de madeira. Quanto aos dados do modelo FPEEEA, foi utilizada a matriz Força Motriz, com os modelos agropecuário, de transporte e energético, condições climáticas adversas e desenvolvimento urbano. No mode- 
lo agropecuário a pressão ocorre pelo desmatamento de grandes extensões de floresta, a abertura de estradas e de usinas de geração de energia, isto ocasiona alterações climáticas provocando uma maior exposição da população a poluentes atmosféricos. Outro modelo de pressão é a forma irregular de ocupação urbana, o modelo agropecuário (soja e pecuária extensiva) provocam queimadas com emissão de poluentes que têm como resultado um ar contaminado, e estes resultados têm como efeito os problemas e riscos à saúde, demandando uma forte pressão por atendimentos hospitalares.

Com todos estes fatores o maior problema é que a população fica exposta à contaminação do ar e à diversos tipos de doenças provocadas pelo desequilíbrio ecológico do município, tendo como resultado um aumento na morbidade e mortalidade por doenças do aparelho respiratório. A pesquisa também levantou dados secundários do relatório de informações de saúde do estado do Mato Grosso, onde pesquisou-se a situação do cenário regionalizado do estado. É importante esclarecer que o escritório regional de saúde de Peixoto de Azevedo têm como abrangência cinco municípios entre eles Guarantã do Norte. De acordo com os dados, Guarantã do Norte tinha em 2009 apenas 1 hospital municipal e 1 privado, para atendimento de uma população no mesmo ano de 32.216 habitantes, com $74,3 \%$ de taxa de urbanização, tendo como quantidade de leitos do SUS na rede hospitalar do município 30 unidades.

Nos resultados obtidos com referência aos índices de desmatamento foram utilizados os dados do INPE em que as queimadas em 2009 atingiram 2387,8 quilômetros quadrados (50,62\%) de perda florestal, em 2012 os índices foram de 4406.0 quilômetros quadrados (51,01\%). O desmatamento no município é continuo, como forma de apropriação de recurso natural e disseminação de doenças provocadas de forma socialmente injusta e ambientalmente incorreta.

\section{Considerações finais}

$\mathrm{O}$ presente estudo trouxe evidências de que a exposição da população ao material particulado fino originário da queima de biomassa (queimadas) está associado ao aumento das internações por doenças do aparelho respiratório em crianças de 0 a 5 anos e idosos com mais de 65 anos, pertencentes ao município de Guarantã do Norte, no norte do Mato Grosso, na
Amazônia Legal.

O modelo de desenvolvimento econômico e de ocupação da região objeto do estudo, favorece o aparecimento de todo tipo de doenças, ocasionadas fortemente pelo vetor desmatamento/queimadas, como visto acontece durante todo o ano, aliado a abertura da BR 163 que impacta toda região. Os resultados obtidos no modelo utilizado o FPEEA sugerem efetivamente algumas ações que devem ser tomadas pelos gestores ou mesmo avaliados os resultados de algumas políticas públicas implementadas na região. Na matriz Força Motriz, as determinantes do modelo agropecuário, de transporte/energético e o desenvolvimento urbano apresentam a necessidade de modificação ou mesmo avaliação das políticas públicas implantadas na região (tais como as de combate ao desmatamento), visto à sua pouco eficiência em conter o aumento do desmatamento na região. Já na determinante condições climáticas adversas, é necessário um investimento maior em programas de monitoramento e controle das condições climáticas. Na matriz Pressão, tendo como determinante o desmatamento, apresenta-se como a prática de ações no sentido da aplicação de leis mais severas para punir os infratores, e este ponto é muito importante, pois a legislação já possui instrumentos como a Lei de Crimes Ambientais, o Código Florestal que preveem formas de punição para o desmatamento de áreas protegidas, queimadas, e tantas outras formas de infração. A falta de uma fiscalização mais efetiva nas três esferas de poder, talvez seja o maior problema, para conter o desmatamento, a falta de recurso humano para fiscalização tem sido, desde sempre, o maior problema para manter a eficácia tanto da legislação pertinente quanto das políticas públicas de controle. Na matriz Estado, a determinante queimadas sugere como ações programas de educação ambiental contínuos na região, primeiro para manutenção da floresta, objetivando a qualidade ambiental e a saúde da população, depois quanto à emissão de poluentes devido à queima de biomassa de combustíveis fósseis, é necessária a implementação de programas para controle das emissões desses poluentes para preservação da saúde da população. Outra ação importante apresentada como resultado na Matriz FEEEAP, é a necessidade de aumento de recursos orçamentários para a saúde, bem como o aumento de profissionais dessa área, aumento do número de hospitais para atendimento da população e investimento em preventivas de saúde e de controle de desmatamento. Na determinante exposição da população 
à contaminação do ar pelas queimadas, são necessários investimentos em monitoramento e controle da qualidade do ar, durante os picos de desmatamento. Por fim, na determinante efeito como morbidade e mortalidade por doenças respiratórias, é necessário aprimorar mais os sistemas de informação voltados para a vigilância em saúde, aumentando os recursos orçamentários e órgãos ambientais, projetos efetivos de educação ambiental de forma permanente na região.

\section{Referências}

ALENCAR, A. et al. Desmatamento na Amazônia: indo além da emergência crônica. Belém: IPAM, 2004.

ARBEX, M. A. et al. Assessment of the effects of sugar cane plantation burning on daily counts of inhalation therapy. Journal Air Waste Manag Assoc, Londres, v. 50, n. 10, p. 1745-1749, trimestral, 2000.

BECKER, Léna P. Pequenos empreendimentos alternativos na Amazônia. Rio de Janeiro: Universidade Federal do Rio de Janeiro; Rede de Sistemas Produtivos e Inovativos Locais, 2002.

DINIZ, Marcelo B. et al. A Amazônia (Legal) brasileira: evidências de uma condição de armadilha da pobreza? In: ENCONTRO NACIONAL DE ECONOMIA, 35, 2007, Recife. Anais... Recife-PE: ANPEC, 2007.

FEARNSIDE, P. M. Global warming and tropical landuse change: greenhouse gas emissions from biomass burning, decomposition and soils in forest conversion, shifting cultivation and secondary vegetation. Climatic Change, Dordrecht, v. 46, p. 115-158, trimestral, 2000.

GEIST H. F.; LAMBIN, E. F. Proximate causes and underlying driving forces of tropical deforestation. BioScience, Washington, v. 52, n. 2, p. 143-150, mensal, 2002.
GONÇALVES, K. S. Queimadas e atendimentos ambulatoriais por doenças respiratórias em crianças no Município de Porto Velho, Rondônia. 2010. Dissertação (Mestrado) - Saúde Pública e Meio Ambiente, Fiocruz, Rio de Janeiro, 2010.

HELMUT J. G.; LAMBIN, E. F. What Drives Tropical Deforestation? A meta-analysis of proximate and underlying causes of deforestation based on subnational case study evidence. LUCC Report Series, Londres, n. 4, 2001.

LAURANCE, W. F. et al. Ecosystem decay of Amazonian forest fragments: a 22-year investigation. Conservation Biology, Boston, v. 13, n. 3, p. 742, trimestral 2002.

LOPES, F. S.; RIBEIRO, H. Mapeamento de internações hospitalares por problemas respiratórios e possíveis associações à exposição humana aos produtos da queima da palha de cana-de-açúcar no estado de São Paulo. Revista Brasileira de Epidemiologia, São Paulo, v. 9, n. 2, p. 215-225, trimestral, 2006.

MAHAR, D. J. Frontier development policy in Brazil: a study of Amazonia. Nova York: Praeger, 1979.

MINAYO, M. C. S.; MIRANDA, A. (Orgs.). Saúde e ambiente sustentável: estreitando nós. Rio de Janeiro: Fiocruz, 2002.

NEPSTAD, D. et al. Road Paving, fire regime feedbacks, and the future of Amazon forests. Forest Ecology and Management, Amsterdam, v. 154, p. 395-407, trimestral, 2001.

SOUZA, S. Análise de Impactos das queimadas sobre a saúde humana: um estudo de caso do município de Rio Branco, Acre. 2008. Dissertação (Mestrado) - Escola Nacional de Saúde Pública, Fiocruz, Rio de Janeiro, 2008. 